\title{
THE POTENTIALITY OF THE "DAPHNE" RAIN ENHANCEMENT PROGRAM IN THESSALY, GREECE
}

DOI: https://doi.org/10.18509/AGB.2019.07

UDC: 551.509.32:004.455]:551.584(495.3)

\section{Theodore S. Karacostas}

Department of Meteorology and Climatology, School of Geology, Faculty of Sciences, Aristotle University of Thessaloniki, Thessaloniki, Greece

corresponding author: karac@geo.auth.gr

\begin{abstract}
The developed Conceptual Model "DAPHNE" is presented. The model "DAPHNE" aims at tackling the problem of drought in the most vital agricultural area of Greece, Thessaly, by means of Weather Modification. It is developed through all the necessary scientific tools to support the potentiality and applicability of a well-designed precipitation enhancement program and to assess thoroughly the impact of its implementation on the environment. Its development relied upon: (i) the 10-year period 2001-2010 surface and upper air meteorological measurements, (ii) the use of the state-of-the-science WRF numerical model with sophisticated microphysical parameterizations, (iii) the adaptation of the 3D cloud model for performing simulations of cloud seeding experiments, (iv) the radar information from a C-band (5-cm) weather radar, through the "TITAN" (Thunderstorm Identification, Tracking, Analysis, and Nowcasting) algorithm and (v) the conduction of instrumented aircraft flights for in-situ measurements and carrying out actual aircraft cloud seeding experiments on suitably chosen appropriate clouds over Thessaly area. Moreover, sampling of precipitated water and consequent soil is performed to investigate the impact of the seeding material on the environment. It is believed, that all these state-of-art tools and aircraft observations have been combined to create the necessary fundamental principles for the development of the "DAPHNE" Conceptual Model that will potentially define the feasibility and applicability of a future rain enhancement program in Thessaly. The developed conceptual model potentially defines -if, when, where and how- a precipitation enhancement program would be applicable over the examined area. It sets the spatial, temporal and meteorological conditions that must be met, so that cloud seeding of appropriate cloud types will be feasible, aiming in precipitation enhancement and mitigation of drought in the major area of Thessaly, Greece.
\end{abstract}

Key words: "Daphne"; conceptual model; weather modification; rain enhancement; Thessaly-Greece.

\section{INTRODUCTION}

The effects of climate change and the continued increase in water needs, for both urban and agricultural use, have largely exhausted water supplies; therefore, an effort must be taken in order to find new ways to augment them. Weather modification has a rather unique status among water resource issues, dealing with cloud seeding that helps clouds more efficiently produce precipitation in the form of rain or snow, or reduce hailstone size in favor of raindrops. The most beneficial and ambitious methodology is that of the precipitation enhancement. In recent years, the development of new sophisticated atmospheric models, in conjunction with modern instruments for recording and measuring atmospheric and cloud physics data have increased the interest in weather modification, and particularly for precipitation enhancement projects [1].
The objective on this study is to present the project DAPHNE, which is focused in the development of necessary scientific tools, to support the potentiality and applicability of a well-designed precipitation enhancement program, by applying state-of-thescience modeling tools, performing measurement campaigns and cloud seeding experiments on suitably chosen appropriate clouds, and investigating the impact of its implementation on the environment. It is applied over the Thessaly plain, which is known as the most vital agricultural area in Greece, where the water needs for urban and agricultural use have been largely exhausted. Hence, weather and climate, through weather modification is called to play a very important role in nation's socio-economic status. Figure 1 partially depicts, in a schematic diagram, the concept and thyme of the project DAPHNE. 


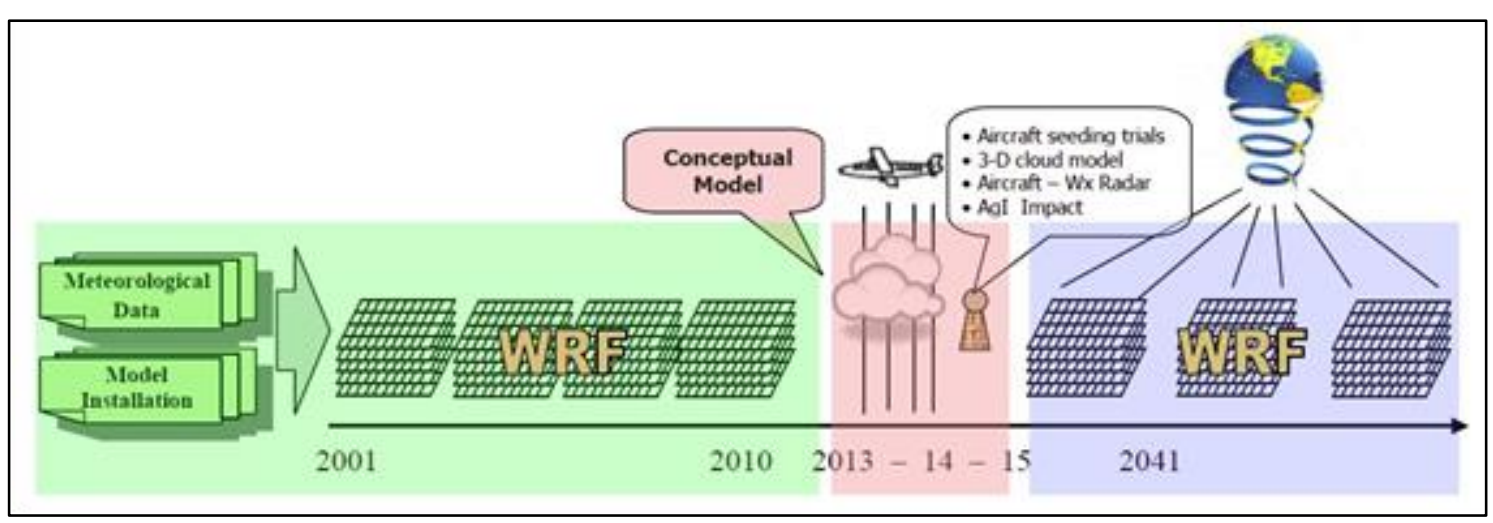

Figure 1. The schematic diagram of the project DAPHNE.

\section{DATA AND METHODOLOGY}

The database of the project DAPHNE includes: a) surface observations from the available manual and automatic meteorological stations of the greater area of Thessaly, b) radiosonde data from the synoptic meteorological station at the airport of Thessaloniki, c) weather radar images received and analyzed from the C-band (5-cm) weather radar, d) specially equipped aircraft measurements (e.g. air temperature, humidity, liquid water content, height, etc.), e) meteorological data (air temperature, precipitation, humidity, atmospheric pressure and wind) from Larissa weather station for a period of 60 years (1950-2010), f) weather charts of daily analyses from ECMWF at $500 \mathrm{hPa}$ at $1200 \mathrm{UTC}$, for the 10-year period 2001-2010, g) gridded analyses from the ECMWF/IFS system for the period 2001-2010, h) gridded projections of RegCM3 regional climate model $(25 \mathrm{~km} \times 25 \mathrm{~km})$ carried out during ENSEMBLES project under the IPCC scenario A1B, for the period 2041-2050, i) chemical samples of soil and water from the seeded and unseeded areas, for environmental impact assessment studies.

The project DAPHNE integrates all contemporary

\section{TECHNOLOGICAL INSTRUMENTATION AND RESULTS}

The non-hydrostatic WRF model with the Advanced Research (WRF-ARW) dynamic solver $[2,3]$ is utilized in the framework of project DAPHNE. The installation is performed on a parallel computing platform (cluster) and all the necessary pre and post-processing modules have been created, taking into consideration the special characteristics of the project.

The model is integrated in three domains, using 2way telescoping nesting, which cover Europe, the Mediterranean Sea and northern Africa (d01), the wider area of Greece (d02) and central Greece Thessaly region (d03), at horizontal grid-spacings of $15 \mathrm{~km}, 5 \mathrm{~km}$ and $1 \mathrm{~km}$, respectively (Fig. 2), utilizing the staggered Arakawa $\mathrm{C}$ grid. Special care components in order to have the most comprehensive state-of-the-science results. These components include the use of the state-of-the-art Weather Research and Forecasting (WRF) numerical model at very high resolution $(1 \mathrm{~km} \mathrm{x}$ $1 \mathrm{~km})$, considering the different types of hydrometeors through sophisticated microphysical parameterizations, the adaptation and redevelopment of a 3D cloud model for performing simulations of seeding material dispersion and high-performance seeding aircraft.

It is the first time that these state-of-the-science tools and aircraft observations are combined in order to create the fundamental principles for the development of the Conceptual Model that define the feasibility potential of a rain enhancement program in Thessaly. The conceptual model will define if, when, where and how a precipitation enhancement program would be applicable over the examined area. It sets the spatial, temporal and meteorological conditions that must be met, so as cloud seeding of appropriate cloud types will be feasible, aiming in precipitation enhancement and mitigation of drought in the area of Thessaly.

has been taken, regarding the spatial definition of the innermost domain, which focus in the area of interest (Thessaly) due to the surrounding complex topography. Fine-resolution (30'x30" and 3'x3"') data are available for the definition of topography and land-use. The initial and boundary conditions of the coarsest domain can be optionally provided by: a) the NCEP/GFS analyses and forecasts (operationally), b) the ECMWF/IFS analyses and c) the RegCM3 regional climate model. ECMWF operational analyses at 6-hourly intervals $\left(0.25^{\circ} \mathrm{x}\right.$ $0.25^{\circ}$ lat.-long.) and NCEP/GFS analyses and forecasts (operationally) can be imported as initial and boundary conditions of the coarse domain. 
The sea-surface temperatures (SSTs) can be provided daily by NCEP (National Centers for Environmental Prediction) at a horizontal resolution of $1 / 12^{\circ} \times 1 / 12^{\circ}, \mathrm{ECMWF}$ analyses or by the RegCM3 fields. The NCEP SSTs are produced on a daily basis through the assimilation of the most recent 24-hours sea-surface observations and satellite SST measurements. In the vertical, all nests employ 39 sigma levels (up to $50 \mathrm{hPa}$ ) with increased resolution in the boundary layer. Microphysical processes are represented by WSM6 scheme, sub-grid scale convection by Kain-Fritsch scheme, longwave and shortwave radiation by RRTMG scheme, surface layer by Monin-Obukhov (MM5), boundary layer by Yonsei University and soil physics by NOAH Unified model.

The Goddard scheme, the Betts-Miller-Janjic scheme, the RRTMG, the Monin-Obukhov (Eta), the Mellor-Yamada-Janjic and the NOAH Unified model are employed in all nests to represent microphysics, sub-grid scale convection, longwave/shortwave radiation, surface layer, boundary layer and soil physics, respectively. The Goddard microphysical scheme [4 and 5] contains separate variables for the calculation of cloud water, rain water, ice, snow and graupel (or hail).

The WRF model is used to produce very high spatiotemporal resolution simulations of the atmospheric conditions in the area of interest and provide the forcing fields to the 3D Cloud model.

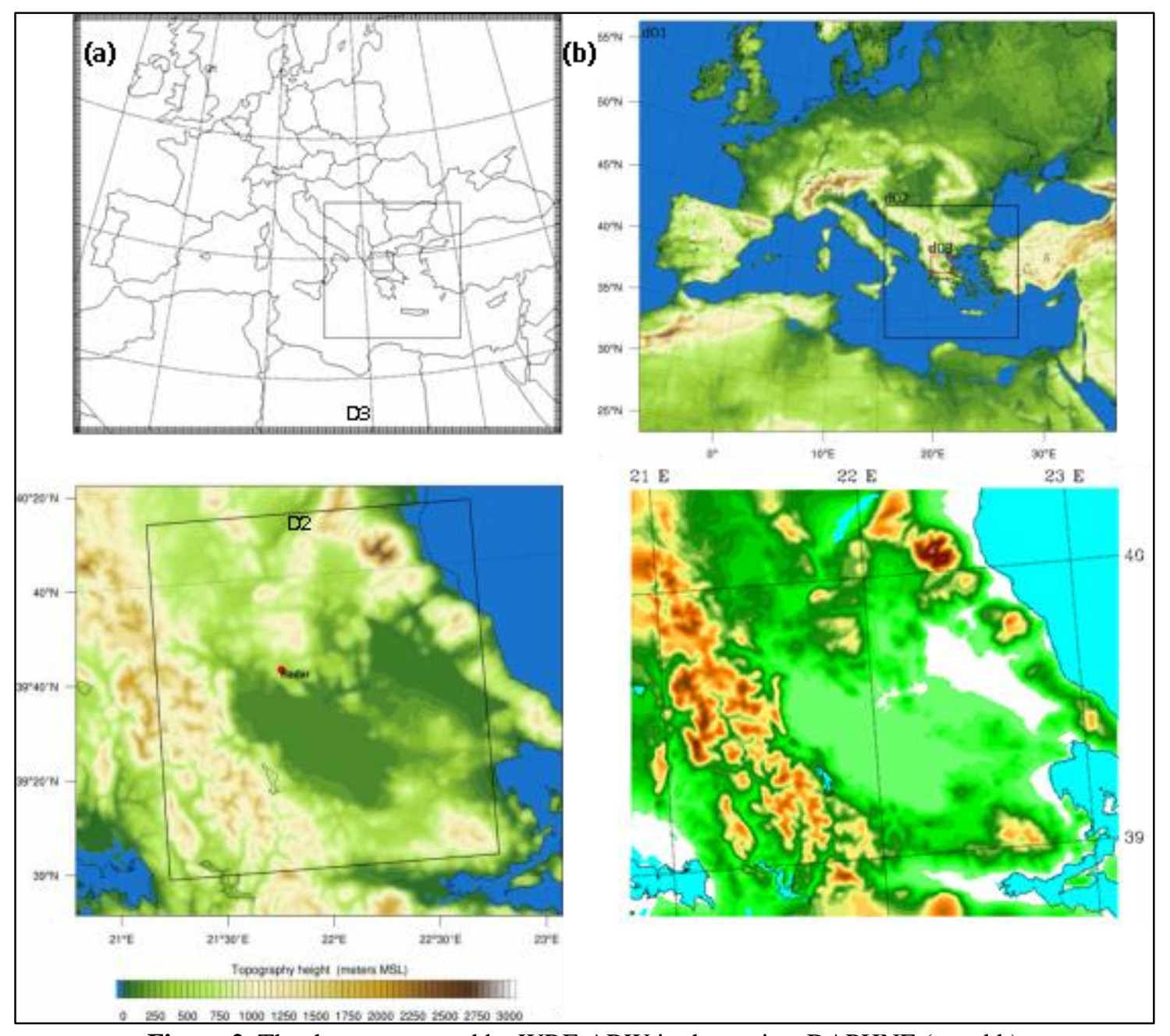

Figure 2. The three nests used by WRF-ARW in the project DAPHNE ( $a$ and $b$ ) and the examined area and topography of the inner domain (D03) (c and d).

The 3D cloud model [6] is a three-dimensional, non-hydrostatic, time-dependent, compressible system, which was initially developed by Telenta and Aleksic [7] and modified by Spiridonov and Curic [8]. It is based on the Klemp and Wilhelmson [9], the bulk cloud microphysics scheme from Lin et al. [10] that takes into account 6 water variables (water vapor, cloud droplets, ice crystals, rain, snow and graupel) and Orville and Kopp [11] thermodynamics. The bulk microphysical parameterization uses a double- moment scheme for all species. The activation of the seeding material, where the AgI has been adopted, is parameterized by the three nucleation mechanisms based on Hsie [12] and Kopp [13] and the calculation of agent dispersion is done using an additional conservation equation. The dispersion of the agent takes place on a sub-grid scale, while the 
advection and diffusion are represented by individual puffs spreading in time according to the turbulent diffusion coefficients proposed by Georgopoulos and Seinfeld [14]. The equivalent radar reflectivity factors for hail and rain are computed according the equations given by Smith et al. [15] and the empirical equation for snow by Sekhon and Srivastava [16]. More detail information about the model, initial and boundary conditions, numerical technique and initialization could be found in Telenta and Aleksic [7], Spiridonov and Curic [6], Barth et al. [17] and Spiridonov et al. [18].

The 3D cloud model is applied to representative cases of past, present and future-projected weather conditions, using the actual radiosonde data of the nearest upper air station (Thessaloniki synoptic station) and the output of the WRF simulations. The cloud model sensitivity to the different sources of input data (radiosonde, WRF) is assessed for the present-weather cases. Initial impulse for convection is an ellipsoidal warm bubble with maximum temperature perturbation in the bubble center. The model domain has dimensions of $60 \times 60 \times 20 \mathrm{~km} 3$, while the spatial grid resolution is $500 \times 500 \times 250 \mathrm{~m}$ and the temporal integration resolution is $5 \mathrm{~s}$ and $10 \mathrm{~s}$, plus a smaller one of $1 \mathrm{~s}$ and $2 \mathrm{~s}$, for solving sound waves.

Storm characteristics are obtained and identified from weather radar reflectivity images received and analyzed from the C-band $(5-\mathrm{cm})$ weather radar, being located at Liopraso area $(39.674 \mathrm{oN}$, $21.837 \mathrm{oE}$; Fig. 2c), within the area of interest. The interfaced cell tracker TITAN (Thunderstorm Identification, Tracking, Analysis, and Nowcasting) (Dixon and Wiener, 1993) has been used to retrieve convective storm tracks and characteristics from radar reflectivity measurements that roughly have $750 \times 750 \mathrm{~m}$ spatial and $3.5 \mathrm{~min}$ temporal resolution. The storm characteristics include: initiation time (UTC hour), duration (minutes), direction $\left(^{\circ}\right)$, speed $(\mathrm{km} / \mathrm{hr})$, volume $\left(\mathrm{km}^{3}\right)$, area and precipitation area $\left(\mathrm{km}^{2}\right)$, rain rate $(\mathrm{mm} / \mathrm{hr})$, maximum reflectivity $(\mathrm{dBz})$, cloud top $(\mathrm{km})$ and many more parameters.

The prevailing synoptic conditions in the greater area of central Greece, during the 10-year period 2001-2010, have been classified, one by one day, according to the general circulation pattern of the middle troposphere. This information was retrieved mainly by daily analyses of ECMWF at $500 \mathrm{hPa}$ at 1200 UTC. The classification is based on the methodology initially introduced by Karacostas et al [19], followed up by Karacostas [20] and Karacostas et al [21]. Adopting the same methodology and procedure, the mid-tropospheric synoptic circulation patterns, projected by the
RegCM3 regional climate model -under the IPCC scenario A1B- during the period 2041-2050, have also been classified. The resulted daily synoptic circulation patterns have been statistically analyzed and compared, in order to investigate the prevailing near-present and future synoptic conditions. To meet the project objectives, representative cases of the near-present and future synoptic conditions were selected and analyzed for the model simulations. Results of such kind of studies have been presented by Karacostas et al [22].

The core experimental work of the project DAPHNE took place from the $1^{\text {st }}$ of March to the $31^{\text {st }}$ of October 2014, with emphasis on the first 45 days and the last 31 , due to the lack of existed previous data information and with the objective to accomplish a complete data set. During these measurement campaigns, the following procedures took place, according to our own operational meteorological forecasts. Appropriate surface and upper air meteorological measurements were performed. Weather radar images were received and analyzed from the C-band $(5-\mathrm{cm})$ weather radar being located at Liopraso area, within the area of interest. Aircraft flights were conducted, by specially instrumented and equipped aircrafts, with specialized on the subject pilots, in order to perform in-situ appropriate measurements. At the same time, and after meeting pre-specified criteria, cloud seeding experiments were carried out on selected clouds. Chemical samplings of soil and water from the seeded area were conducted, and impact study analyses were performed. Sampling from the surrounding background areas was also performed for comparison purposes.

It is believed and also proven that the aforementioned field experiments and measurement campaigns, coupled with numerical model simulations and proper seeding technologies and procedures, very well support the main objective of the project DAPHNE. Figure 3 depicts only some of the aforementioned storm measurements, synthesized together with the 10year data information, for the south-west (SW) upper-air synoptic circulation type. Similar analyses and presentations have been conducted for each one of the upper-air synoptic circulation types encountered throughout the DAPHNE project.

An investigation concerning the impact of the seeding material on the environment has been conducted, by sampling of precipitated water and consequent soil, immediately after the cloud seeding performance. It is known that the Silver Iodide (AgI) determination in complicated samples like soils containing important amounts of organic matter, is not an easy task, which becomes more difficult, taking into account the extremely low 
concentrations of the dispersed amount of $\mathrm{AgI}$ in the total precipitation and furthermore in the large mass of ground soil. Hence, soil samples were collected according to the standard sampling procedure from two types of areas: (a) from sampling sites inside the targeted area, where the cloud seeding project is applied and (b) from sampling sites outside the targeted area, where no cloud seeding has been applied ever, and analyzed for their silver concentrations. In addition, precipitated water samples after seeding procedures were also collected and analyzed in an analogous manner, for the same purpose and objectives. Although total silver (Ag) was measurable in almost all soil samples, the concentrations were found in average levels. On the other hand, no silver iodide (AgI) residues were detected. Regarding surface water samples, no detectable silver $(\mathrm{Ag})$ concentration was found [23].

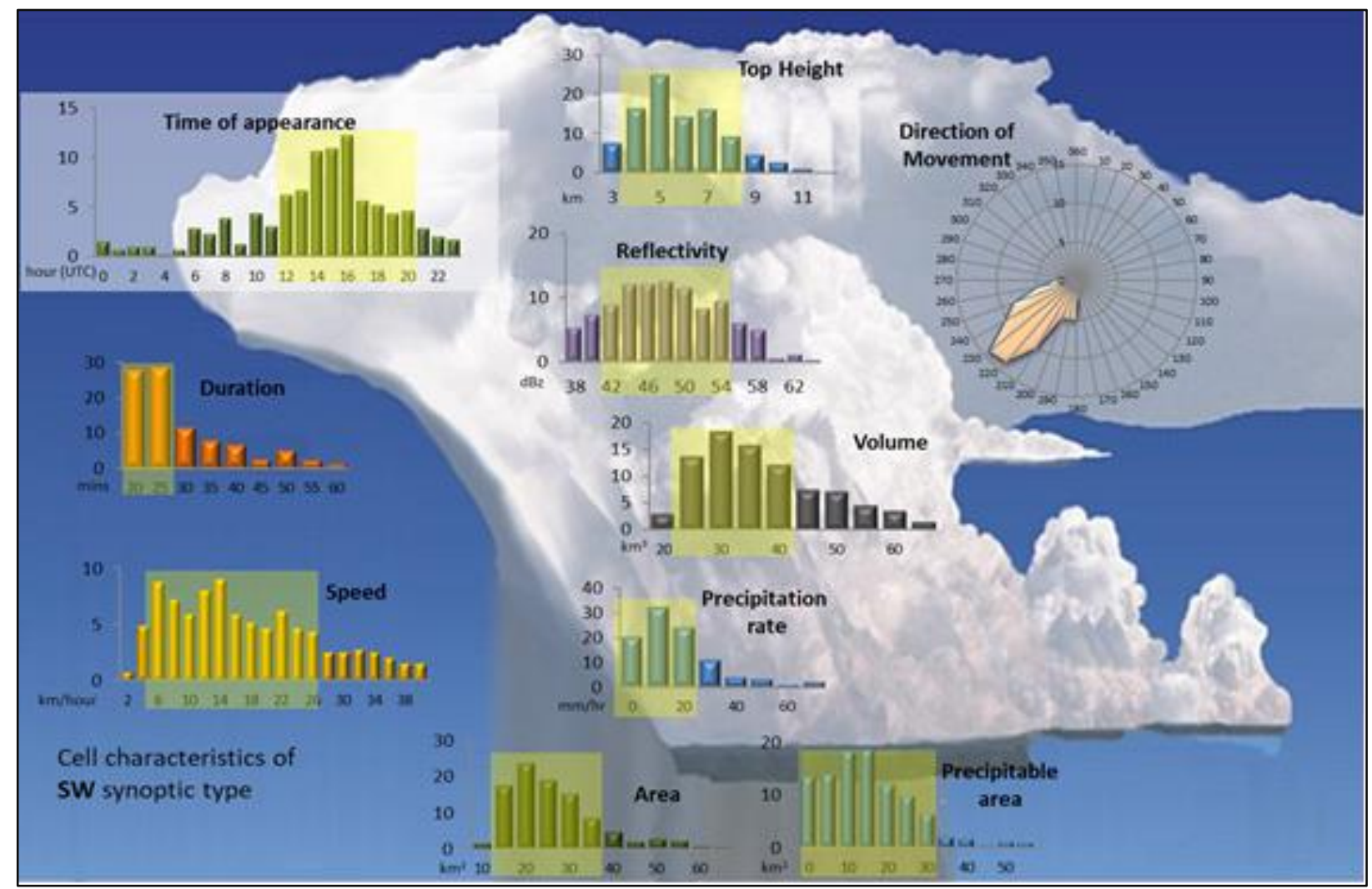

Figure 3. Storm characteristics, synthesized from the 10-year data information, for the south-west (SW) upper-air synoptic circulation type, for the project DAPHNE.

Furthermore, the use of the state-of-the-science numerical weather prediction model (WRF-ARW ver3.5.1), which was simulated and operationally predicted the characteristics of convective activity, showed to be in good agreement with observations, enhancing thus the scientific knowledge [24]. Sensitivity tests, which were also performed by Tegoulias et al [25], exhibited good agreement

\section{THE "DAPHNE" RAIN ENHANCEMENT CONCEPTUAL MODEL}

The main objective of the DAPHNE project was to integrate, in a state-of-the-art manner, all the presented contemporary scientific components, in order to have the most comprehensive state-of-thescience results, in the form of the "DAPHNE" rain enhancement Conceptual Model, emerging throughout the analyzed and studied data information. Some of these components are: the use between actual and simulated values. Moreover, the adoption of the 3D cloud model, acted as a valuable tool at investigating responses on cloud dynamical and microphysical features, making possible to measure and test precipitation enhancement against different seeding methods, rates and locations [26 and 27].

of the state-of-the-art WRF numerical model with sophisticated microphysical parameterizations, the adaptation of the 3D cloud model for performing simulations of cloud seeding experiments, the radar information from the C-band $(5-\mathrm{cm})$ weather radar through the TITAN algorithm, the conduction of instrumented aircraft flights for in-situ measurements by carrying out actual cloud seeding 
experiments and last but not least, to investigate the impact of the seeding material on the environment. It is strongly believed, that it is for the first time that all these state-of-the-science tools and aircraft observations are combined, in order to create the necessary fundamental principles for the development of the conceptual model that would actually define the feasibility potential and applicability of a rain enhancement program in Thessaly. Hence, the "DAPHNE" rain enhancement Conceptual Model specifically defines -if, when, where and how- a precipitation enhancement program would be applicable over the examined area. It sets the spatial and temporal meteorological conditions that must be met, so that, cloud seeding of appropriate cloud types will be feasible, aiming in precipitation enhancement and mitigation of drought in the area of Thessaly.

The schematic diagram of the "DAPHNE" rain enhancement Conceptual Model, indicating the potentiality and applicability of a rain enhancement program in Thessaly, is fully demonstrated in Figure 4. The incorporated arithmetic "typical" values correspond to cloud characteristics with reflectivities greater than $35 \mathrm{dBz}$.

Combining the results from the analyses into discrete categories and factors, the hydro-climatic factor suggested that a rain enhancement program should be applied over the examined area during the period of increased water needs and when soil moisture deficit becomes evident. Relying upon the characteristics depicted on Figure 4, this period seems to be oriented from March to October. Actually, the period from 10 of March to 20 of October is proposed as the feasible period for conducting a rain enhancement program in the area of Thessaly, Greece.

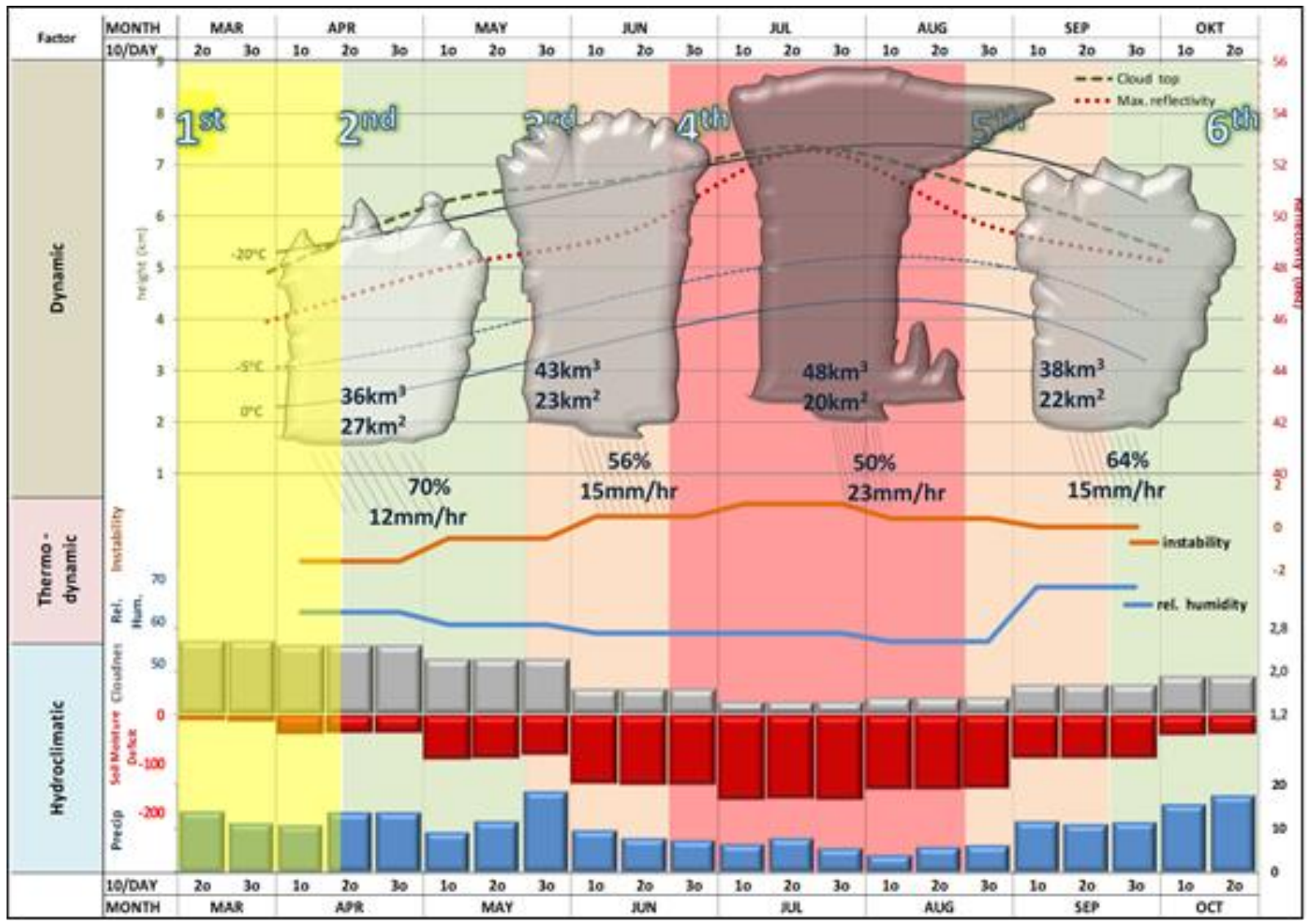

Figure 4. A schematic diagram of the "DAPHNE" rain enhancement

Conceptual Model in the area of Thessaly, Greece.

The synoptic factor, expressed mainly by the magnitude of the frontal systems that pass over the area and the associated other synoptic features, suggests that the application of a program over well-organized weather systems would have little impact on precipitation enhancement, since such systems are capable by themselves of producing large and widespread amounts of precipitation. Conversely, weather systems during the so called warm period (March to October, for the examined area) exhibit convective and dynamical characteristics, and therefore, these systems are amenable for cloud seeding.

The thermodynamic factor, denoting the atmospheric instability, is maximized during the warm period, reaching its maximum values during July (Figure 4). Storms developing under conditions of high atmospheric instability are also 
not eligible to conduct cloud seeding, since such storms can effectively produce precipitation and sometimes even damaging hail. Of course, not all weather systems are dynamically strong enough and hence, atmospheric instability is not always too high to prevent the application of a rain enhancement program.

According to the dynamic and microphysical factors, the clouds developing over the area meet all the necessary conditions related to upward motion and horizontal and vertical extent, appropriate cloud base and cloud top temperatures and reflectivity values, in order to perform a rain enhancement program. The primary reason for cell characteristics differentiations is the time of appearance within the period of study and secondly the synoptic and dynamic conditions for the cells' development. Therefore, based upon the aforementioned factors and characteristics, the "DAPHNE" rain enhancement Conceptual Model could be differentiated in time into the following six (6) sub-periods, providing thus the opportunity to introduce and apply altered concepts on physical hypotheses and even different seeding rates:

$1^{\text {st }}$ sub-period: 10 March - 10 April

$2^{\text {nd }}$ sub-period: 11 April - 25 May

$3^{\text {rd }}$ sub-period: 26 May - 25 June

$4^{\text {th }}$ sub-period: 26 June - 25 August

$5^{\text {th }}$ sub-period: 26 August -25 September

$6^{\text {th }}$ sub-period: 26 September - 20 October

During the $1^{\text {st }}$ period, cells tend to develop due to synoptic conditions, mainly within frontal systems as embedded convective areas. These cells are almost evenly distributed day and night. Part of the

\section{SYMMARY AND CONCLUSIONS}

The implementation scope of the project DAPHNE is to tackle the problem of drought in Thessaly by the scientific means of weather modification. The Thessaly plain is known to be a vital agricultural area in Greece, and thus the weather and climate play a very important role in its socio-economic status. Anthropogenic climate change is expected to further deteriorate the problem of drought and water shortage, posing a serious threat in human and agricultural activities. It appears, thus, a necessity to investigate the potential impact of present weather and climate change on drought, in order to suggest effective ways of tackling the already existed -and for sure- future problem.

The synthesis of all the available data that was performed during the period of the project DAPHNE has resulted in the formation of the conceptual model. According to the DAPHNE Conceptual Model, a precipitation enhancement program could potentially be applied over the area of Thessaly-Greece from the $10^{\text {th }}$ of March to the $1^{\text {st }}$ period and mainly during the $2^{\text {nd }}$ period, the cells are almost evenly distributed during the day and usually extend from $1.3 \mathrm{~km}$ up to $6 \mathrm{~km}$. Mean volume of these cells is about $36 \mathrm{~km}^{3}$, mean area 27 $\mathrm{km}^{2}$ and precipitation rate about $12 \mathrm{~mm} / \mathrm{hr}$, covering almost the $70 \%$ of their total precipitation area. During the $3^{\mathrm{d}}$ period, convective cells appear mainly due to atmospheric instability during the warm hours of the day and secondly from the weather systems. They indicate greater vertical extent, compared to the previous ones, reaching heights up to $8 \mathrm{~km}$, resulting in bigger cloud volume: $43 \mathrm{~km}^{3}$, but less area: $23 \mathrm{~km}^{2}$ and even less precipitation area $(56 \%)$, but with higher precipitation rate: $15 \mathrm{~mm} / \mathrm{hr}$. In the $4^{\text {th }}$ period, which is the heart of the warm season, isolated convective cells develop mostly as a result of atmospheric instability, exhibiting the strongest characteristics, with tops up to $9 \mathrm{~km}$ and sometimes even more, volume of $48 \mathrm{~km}^{3}$, area of $20 \mathrm{~km}^{2}$, and even less precipitation area $50 \mathrm{~km}^{2}$, with the highest encountered precipitation rate of $23 \mathrm{~mm} / \mathrm{hr}$. In the $5^{\text {th }}$ and $6^{\text {th }}$ periods, the convective cells gradually lose some of their strength characteristics, as atmospheric instability decreases with time period. Their characteristics lie among those encountered between the $3^{\mathrm{d}}$ and the $2^{\text {nd }}$ period, as they are influenced by both, atmospheric instability and frontal systems. Hence, they reach heights up to about $7 \mathrm{~km}$, with cloud volume $38 \mathrm{~km}^{3}$ and area of $22 \mathrm{~km}^{2}$. The encountered precipitation rate drops gradually down to $15 \mathrm{~mm} / \mathrm{hr}$, covering at the most a precipitation area of $64 \%$ of the total one.

$20^{\text {th }}$ of October.

Six consecutive time periods appear to consist the yearly operational period, demonstrating thus the necessity for similar, different, or at least modified seeding hypothesis, according to the storm's synoptic, dynamic, thermodynamic and microphysical characteristics.

One of the main and proven concluding remarks is that the cells' characteristics are being primarily altered in time, seasonally and mainly through the synoptic, dynamic, thermodynamic and microphysical processes of cells' developments. Thus, the feasible application period has been divided into six (6) sub-periods, due to changes in cloud characteristics, as these are depicted within the DAPHNE Conceptual Model (Figure 4). The most favorable sub-periods for application are: $2^{\text {nd }}$, $3^{\text {rd }} 5^{\text {th }}$ and $6^{\text {th }}$ sub-periods. The $1^{\text {st }}, 2^{\text {nd }}$ and $6^{\text {th }}$ subperiods are mostly dominated by the synoptic factor, the $4^{\text {th }}$ sub-period by the thermodynamic and microphysical factors, while all the aforementioned 
factors affect the $2^{\text {nd }}, 3^{\text {rd }}$ and $5^{\text {th }}$ sub-periods, as well. It is intuitively true that all the aforementioned are expected to be fully develop and emphasize the strong interaction between cloud dynamics and microphysics, especially in small scale processes, which influence seeding agent transport and diffusion within the storm's complex environment. Seeding effects are strongly depended upon the seeding strategy, relying on the exact seeding time, the right placement of the seeding agent and the appropriate seeding rate.

The analyses performed within the project DAPHNE constitute the scientific part which is the most vital component before conducting a weather modification program. A techno-economical study is of paramount importance and necessary, in order to evaluate all costs associated with the application of the program, before the decision to proceed with an operational weather modification program is made.

Acknowledgments This research work of DAPHNE project is co-funded by the European Union (European Regional Development Fund) and Greek National Funds, through the action "COOPERATION 2011: Partnerships of Production and Research Institutions in Focused Research and Technology Sectors" in the framework of the operational programme "Competitiveness and Entrepreneurship" and Regions in Transition (OPC II, NSRF 20072013).

\section{REFERENCES}

[1] Silverman, B.A. A Critical Assessment of Hygroscopic Seeding of Convective Clouds for Rainfall Enhancement. Bulletin of the American Meteorological Society, 1219-1230, 2003.

[2] Skamarock, W.C., Klemp, J.B., Dudhia, J., Gill, D.O., Barker, D.M., Duda, M.G., Huang, X-Y., Wang, W., Powers, J.G. A description of the Advanced Research WRF Version 3. NCAR/TN-475, 2008.

[3] Wang, W., Bruyère, C., Duda, M., Dudhia, J., Gill, D., Lin, H.-C., Michalakes, J., Rizvi, S., Zhang, X., Beezley, J., Coen, J. and Mandel, J. ARW Version 3 Modeling System User's Guide. NCAR-MMM. 352 pp., 2010.

[4] Tao, W-K and Simpson, J. The Goddard cumulus ensemble model. Part I: Model description. Terr. Atmos. Oceanic Sci., 4, 35-72, 1993.

[5] Tao, W-K., Simpson, J, Baker, D., Braun, S., Chou, M.-D., Ferrier, B., Johnson, D., Khain, A., Lang, S., Lynn, B., Shie, C.-L., Starr, D., Sui, C.-H., Wang, Y., and Wetzel, P. Microphysics, radiation and surface processes in the Goddard Cumulus Ensemble (GCE) model. Meteor. and Atmos. Phys., 82, 97-137, 2003.

[6] Spiridonov, V., and Curic, M. A three-dimensional modeling studies of hailstorm seeding. J. Weather. Modif., 38, 31-37, 2006.

[7] Telenta, B., and N. Aleksic. A three-dimensional simulation of the 17 June 1978 HIPLEX case with observed ice multiplication, $2^{\text {nd }}$ International Cloud Modelling Workshop, Toulouse, 8-12 August 1988. WMO/TD No. 268, 277$285,1988$.

[8] Spiridonov, V., and Curic, M. Application of a cloud model in simulation of atmospheric sulfate transport and redistribution. Part I. Model description. Idojaras Quart, 107, 2, 85-115, 2003.

[9] Klemp, J.B., Wilhelmson, R.B. The simulation of three-dimensional convective storm dynamics. J. Atmos. Sci., 35, 1070-1096, 1978.

[10] Lin, Y-L., Rarley, R.D., Orville, H.D. Bulk parameterization of the snow field in a cloud model. J. Appl. Meteorol., 22, 1065-1092, 1983.

[11] Orville, H.D., Kopp, F.J. Numerical simulation of the history of a hailstorm. J. Atmos Sci., 34, 1596-1618, 1977.

[12] Hsie, E.Y., Farley, R.D., Orville, H.D. Numerical simulation of ice-phase convective cloud seeding. J. Appl. Meteorol., 19, 950-977, 1980.

[13] Kopp, F.J. A simulation of Alberta cumulus. J. Appl. Meteorol., 27, 626-641, 1988.

[14] Georgopoulos, P.G., and Seinfeld, J.H. Mathematical modeling of turbulent reacting plumes - general theory and model formulation. Atmos. Environ., 20, 1791-1802, 1986.

[15] Smith, P.L., Myers, G.G., Orville, H.D. Radar reflectivity calculations on numerical cloud models using bulk parameterization of precipitation. J. Appl. Meteor., 14, 1156-1165, 1975.

[16] Sekhon, R.S., Srivastava, R.C. Snow size spectra and radar reflectivity. J. Atmos. Sci., 27, 299-307, 1970.

[17] Barth, M.C., Kim, S-W., Wang, C., Pickering, K. E., Ott, L. E., Stenchikov, G., Leriche, M., Cautenet, S., Pinty, JP., Barthe, Ch., Mari, C., Helsdon, J. H., Farley, R. D., Fridlind, A. M., Ackerman, A. S., Spiridonov V., Telenta B. 
Cloud-scale model intercomparison of chemical constituent transport in deep convection, Atmos. Chem. Phys., 7, 4709-4731, 2007.

[18] Spiridonov, V., Karacostas, T., Bampzelis, D., Pytharoulis, I. Numerical Simulation of Airborne Cloud Seeding over Greece, Using a Convective Cloud Model, Asia-Pac. J. Atmos. Sci., 51(1), 1-17, 2015.

[19] Karacostas, T.S., Flocas, A.A., Flocas, H.A., Kakaliagou, O., Rizou, C. A study of the synoptic situations over the area of Eastern Mediterranean, Proc., 1st Greek Conf. on Meteorology Climatology and Atmospheric Physics, Thessaloniki-Greece, 469-477, 1992 (in Greek).

[20] Karacostas, T.S. The Greek National Hail Suppression Program: design, physical hypothesis and statistical evaluation. In: Regional Seminar on Cloud Physics and weather modification. World Meteorological Organization, WMP No. 42, WMO-TD No. 1227, 213 pp., 2003.

[21] Karacostas, T., Kartsios, S., Pytharoulis, I., Tegoulias, I., Bampzelis, D. Observations and modelling of the characteristics of convective activity related to a potential rain enhancement program in central Greece. Atmospheric Research. 208, 218-228. DOI: 10.1016/j.atmosres.2017.08.014, 2018.

[22] Karacostas, T., I., Pytharoulis, I., Tegoulias, S., Kartsios, D., Bampzelis and K., Tympanidis. Near-present and future precipitation characteristics in Thessaly area, being related to the upper-air synoptic circulation types. $14^{\text {th }}$ International Conference on Meteorology, Climatology and Atmospheric Physics, Alexandroupolis, Greece, 918923, 2018.

[23] Anthemidis, A. N., G.A., Zachariadis, T., Karacostas, A.G., Zachariadis, J.A., Stratis. Trace Silver Determination in Surface Soil Matrices by Electrothermal Atomic Absorption Spectrometry. 9th Aegean Analytical Chemistry Days, Chios, 2014.

[24] Pytharoulis, I., Tegoulias, I., Kotsopoulos, S., Bampzelis, D., Karacostas, Th., Katragkou, E. Evaluation of the operational numerical weather predictions of theWaveForUs project. 12th International Conference of Meteorology, Climatology and Physics of the Atmosphere, Heraklion, Greece, vol. 3, 96-101, 2014.

[25] Tegoulias, I., Pytharoulis, I., Bampzelis, D., Karacostas, T. Evaluation of Numerical Weather Predictions Performed in the context of the project DAPHNE, Geophysical Research Abstracts, Vol. 16, EGU2014-5637, EGU General Assembly, Wien, Austria, 2014.

[26] Bampzelis, D., Spiridonov, V., Kartsios, S., Pytharoulis, I., Tegoulias, I., Karacostas, T. Numerical Simulation of Airborne cloud Seeding for the DAPHNE Precipitation Enhancement Project in central Greece, 95 ${ }^{\text {th }}$ AMS Annual Meeting, Phoenix, Arizona, USA, 2015.

[27] Spiridonov, V., Karacostas, T., Bampzelis, D., Pytharoulis, I. Numerical Simulation of Airborne Cloud Seeding over Greece Using a Convective Cloud Model. Asia-Pac. J. Atmos. Sci., 51(1), 1-17, 2015. 